\title{
Properties of Resinous Wood Species Used in OSB Technology
}

\author{
Bogdan IANCU \\ Kronospan Brasov, Romania, iancu bogdan28@yahoo.com \\ Aurel LUNGULEASA \\ Transilvania University of Brasov, Romania, lunga@unitbv.ro \\ Elena MUSAT \\ Transilvania University of Brasov, Romania, david elenabv@yahoo.com \\ Cosmin SPIRCHEZ \\ Transilvania University of Brasov, Romania, cosmin.spirchez@unitbv.ro
}

\begin{abstract}
The paper aims to discover the characteristics of softwood species used in the technology of oriented strand board. In this sense, the main physical-mechanical properties of three wood species (fir, spruce, and pine) were determined and obtained, based on the European standards. The physical properties of the solid wood will be compared with the characteristics of the oriented strand boards obtained from each resinous wood species, in a future work. From the analysis of wood properties, it was found that the softwood species are the best corresponding specie to this technology, because they have soft and light wood (due to their low density), and their higher mechanical strength will give very good mechanical strength of the boards. As a final conclusion of this work, it can be stated that the softwood species remain the basic species of the technology for the manufacture of oriented wood strand boards, due to their low density (thus good compressibility and compactness) and superior mechanical properties.
\end{abstract}

\section{Keywords}

OSB, wood specie, MOR, MOE, IB

\section{Introduction}

The oriented strand boards (OSB) are composite boards obtained from a mixture of long chips (strand) with adhesive and hot pressed. These boards have taken a great advantage in the last period of time, due to the fact that it has replaced other expensive boards in its uses, especially in the constructions. At European level there is the ISO 16864: 2016 [1] standard, which explains the manufacturing requirements of OSB boards and divides these boards into four categories, depending on their properties. In the same sense, EN 300:2006 [2] divides the OSB boards into four categories, two for indoor boards and two for moisture resistant exterior boards. Within each category of OSB board, it is one category for small loads and another one for large loads (used in roof constructions and high strength beams). The OSB boards consist of three distinct layers, two for exterior and one for core. The faced chips are larger and are longitudinally oriented, and the core layer is made up of smaller chips, arranged perpendicular to the face layers. This makes the OSB have properties that are appropriate in both longitudinal and transverse directions, resembling plywood from this point of view. That is why the uses of OSB boards start from this property, resulting in applications in light constructions, overhangs, barracks, savannahs and wooden houses.

Barnes 2000 [3] has developed a mathematical model with eight equations for predicting OSB properties according to the wood species used by eight factorial parameters, of which the most important were wood density, wood strength, resin content, dimension of strands and the angular deviation of strands. Beck et al. 2009 [4] compared two low density beach boards (aspen) and one medium density boards (birch), using strands with three lengths of 78, 105 and $142 \mathrm{~mm}$ and two thicknesses of 0.55 and $0.75 \mathrm{~mm}$. The highest strengths (modulus of rupture-MOR, modulus of elasticity- MOE, compressive strength, stiffness and internal bond -IB) were obtained for birch, and long and thin strands. Bufalino (2015) [5] has investigated the mixing strands of three common species (Red cedar, Eucalyptus and pine), to obtain OSB boards. Research has shown that eucalyptus can replace pine wood, but Red cedar describes mechanical performance. Dixon et al 2017 [6] found a 
model for meso bamboo OSB board from the point of modulus of elasticity, on major and minor axis. All the determinations were made in accordance with EN 300: 2006, and the boards made from high density species showed better physical performances, while the boards made from low density wood species had high mechanical properties.

The main objective of the paper is to find one of three wood species of softwoods used in OSB technology, which will be better by their properties. The physical properties of the wood (swelling and water absorption, density), as well as mechanical ones (resistance and modulus of elasticity to bending) will be taken into account in this regard.

\section{Materials and Methods}

Three wood species were used of softwoods (fir, spruce, pine). Thin logs were chosen from the raw material base of Kronospan Romania Company in Brasov, with specific activity of manufacturing of OSB boards. The log diameters used for the tests were between $25-30 \mathrm{~mm}$. From the logs were cut strips with the section of $20 \times 20 \mathrm{~mm}$, and from these were cut specimens for moisture content, density and higroscopicity at $100 \mathrm{~mm}$, and for static bending at $300 \mathrm{~mm}$.

Determination of the density of solid wood (EN 323: 1993) [7]. The test for determining the density or volume mass of bulk wood was based on the determination of the mass and volume of the specimens, using the following equation:

$$
\rho=\frac{m}{l \cdot w \cdot t} 10^{6}\left[\mathrm{~kg} / \mathrm{m}^{3}\right]
$$

where: $m$ - mass of sample (g); $w$ - width of sample (mm); $t$ - thickness of sample (mm).

Determination of water absorption and swelling in thickness (EN 317) [8]. For this determination it was used a container with clean water and the possibility of submerging the pieces below the water level, at $1 \mathrm{~cm}$. First, the specimens were dried in the oven at $105^{\circ} \mathrm{C}$ for 24 hours, after which the mass and dimensions of the cross-section of the specimens were determined. The specimens were then immersed in water for a period of 24 hours. Based on the initial and final masses and dimensions, water absorption and swelling in thickness were determined with the next relations:

$$
A=\frac{m_{i}-m_{f}}{m_{i}} \cdot 100 \quad[\%] U_{g}=\frac{t_{i}-t_{f}}{t_{i}} \cdot 100 \quad[\%]
$$

where: $m_{i}$ - initial mass of samples before immersion, in g; $m_{f}$ - final mass of sample after immersion in g; $g_{i}$-initial thickness of samples before immersion, in $\mathrm{mm} ; g_{f}$-final thickness of samples, in mm.

For whole board, the arithmetic mean of all 10 tested samples was made; the results were expressed in whole values, also registering with the average value the standard deviation and the extreme values, respectively the maximum and minimum value of the tested sample lot.

Determination of MOR and MOE for bending strength. For both tests (MOR and MOE), the universal test machine IMAL IB 600 was used that is also used for other tests of solid wood and composite boards. For the mechanical tests, specialized devices for the determination of the resistance to static bending and of the modulus of elasticity, respectively the two lower supports and the upper punch of applying the force, with a diameter of $30 \mathrm{~mm}$ are attached to this machine. The formula used to obtain MOR was the following:

$$
\sigma_{i}=\frac{3}{2} \cdot \frac{P l}{b h^{2}} \quad[M P a]
$$

where: $P$ is the maximum effort below which the specimen will be broken, in $\mathrm{N}$; $l$ - the distance between supports, equal to $240 \mathrm{~mm} ; b$ - base of the cross-section of the specimen, expressed in $\mathrm{mm}$; $h$ - height of the specimen in cross-section.

The principle of the test for determining the modulus of elasticity at static bending is based on measuring the deformation under load, the specimen being placed on two supports and the load being applied in two points of the wooden specimen. The modulus of elasticity at static bending is 
determined on prismatic specimens having a length of $300 \mathrm{~mm}$ and a square section of $20 \mathrm{~mm}$. The modulus of elasticity (MOE) for static bending is calculated with the following relation:

$$
E_{i}=\frac{23}{108} \cdot \frac{P l^{3}}{b h^{3} f_{m}} \quad[M P a]
$$

where: $P^{`}=P_{\max }-P_{\min }=600-200=400 \mathrm{~N}$, is the difference between the two forces, in $\mathrm{N} ; l-$ the distance between supports is $240 \mathrm{~mm}$; b-width of the cross-section, in $\mathrm{mm}$; $h$ - the height of the crosssection; $f_{m}$ - the average deformation corresponding to the force of $400 \mathrm{~N}$, expressed in $\mathrm{mm}$.

\section{Results and Discussion}

The properties of the solid wood used in OSB manufacturing are referred to humidity, density, higroscopicity (water absorption, thickness swelling), MOR and MOE. The humidity of the wood when determining its characteristics was around $10 \%$.

\subsection{Water absorption}

Case of fir species (Figure 1). It has been clearly observed that the swelling in the two directions (tangential and radial) is the same of $4.3 \%$, which means that the fir wood is very homogeneous. The water absorption of this specie, $63.9 \%$ seems to be quite high, but the best analysis of the absorption is the comparative one, with the other two woody species.
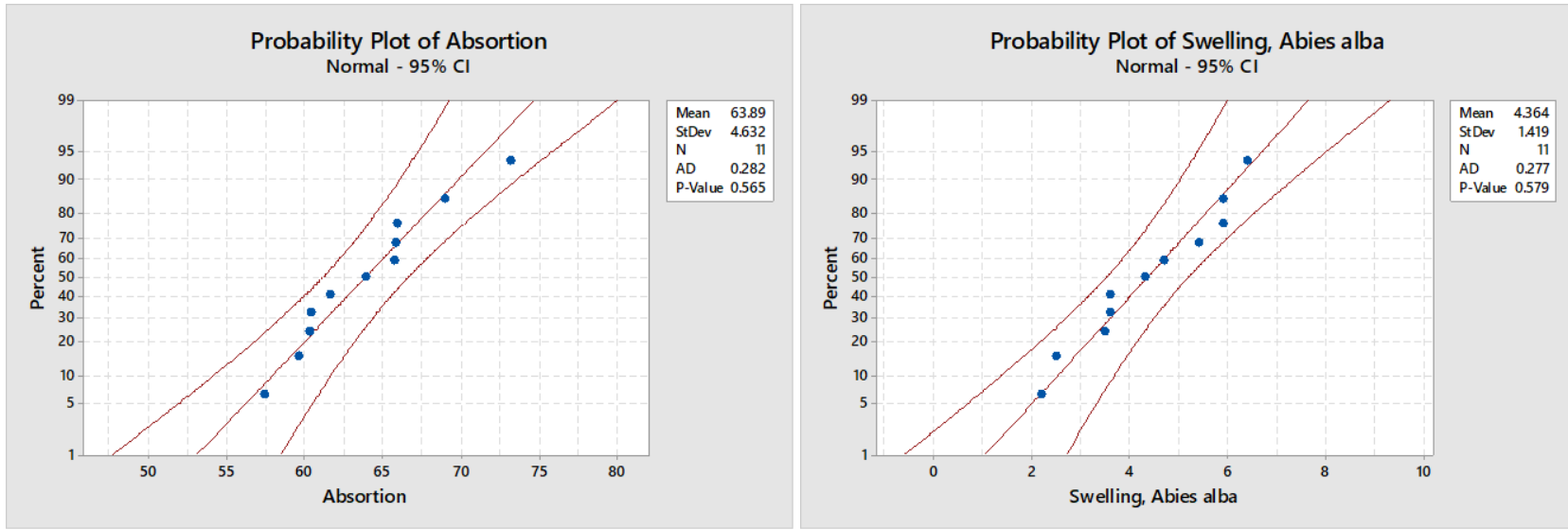

Fig. 1. Water absorption and thickness swelling for fir (Abies alba)
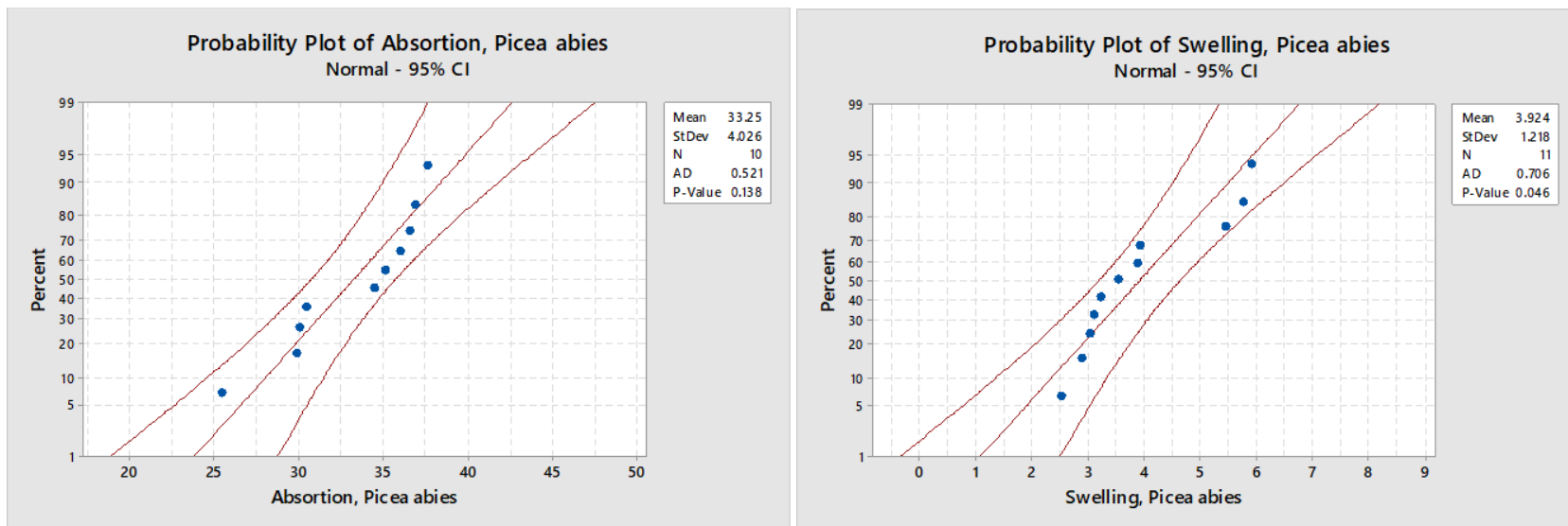

Fig. 2. Water absorption and thickness swelling of spruce (Picea abies)

Case of spruce species (Figure 2). The values of water absorption were as average of $33.25 \%$, and the thickness swelling in the direction D1 was 3.92\% and on D2 $3.17 \%$ for this spruce. Regarding the water absorption of spruce, the average value of $33.25 \%$ is much lower than that of the fir, this being 
due to the significant differences in density between the two species. The swelling in thickness was different on the two directions D1 and D2 due to the clearer highlighting of the two directions, respectively the tangential and radial on the cross section of the specimen.

Case of pine species. Water absorption had a value of $53.46 \%$, higher than that of spruce wood, but smaller than that of fir wood. Thickness swelling had a value of $4.38 \%$ in the D1-tangential direction and 3.18\% in the radial-D2 direction. Considering the combination of the three species of softwoods (fir, spruce and pine) it can be put on the same graph both the swelling and the average shrinkage of the wood, as shown in Figure 3a. There is an average hysteresis between the swelling and shrinkage of the wood of about $0.8 \%$ in absolute values.

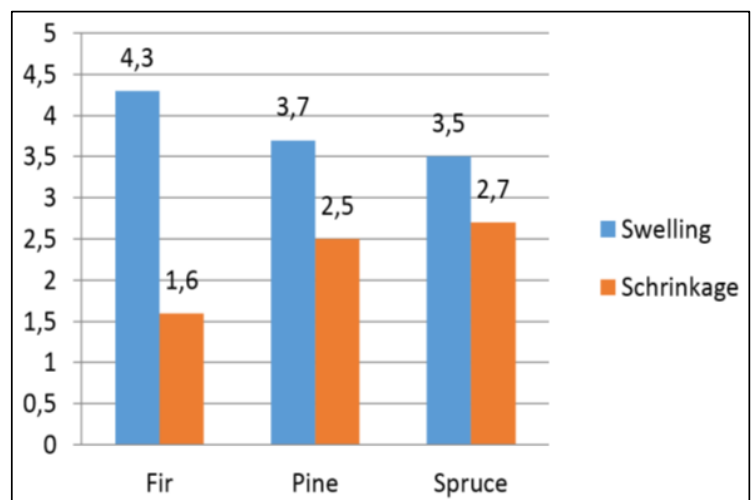

a.

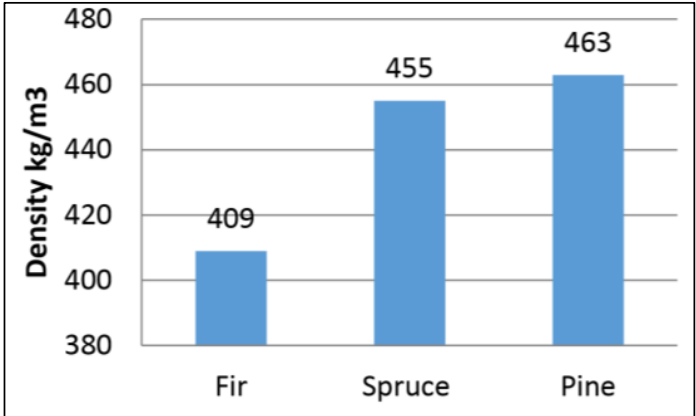

b.

Fig. 3. Swelling and shrinkage of resinous wood (a) and wood density (b)

If it makes a comparative analysis of the swelling and shrinkage of the wood of the three wood species, it can observe a maximum of the values for pine, but the differences from the other two species of wood are insignificant. From this point of view of the swelling in thickness the three woody species are almost homogeneous.

\subsection{Wood density}

All densities of resinous solid wood were over $400 \mathrm{~kg} / \mathrm{m}^{3}$. These species are belonging to the low density species category, below $500 \mathrm{~kg} / \mathrm{m}^{3}$, as seen in Figure $3 \mathrm{~b}$.

\subsection{Modulus of resistance (MOR) and modulus of elasticity (MOE) for bending strength.}

MOR for the three species analyzed was approximately equal to $65 \mathrm{~N} \cdot \mathrm{mm}^{2}$ and MOE for all three resinous wooden species was about $6500 \mathrm{~N} / \mathrm{mm}^{2}$, as it can see as example in Figure 4, for spruce species.
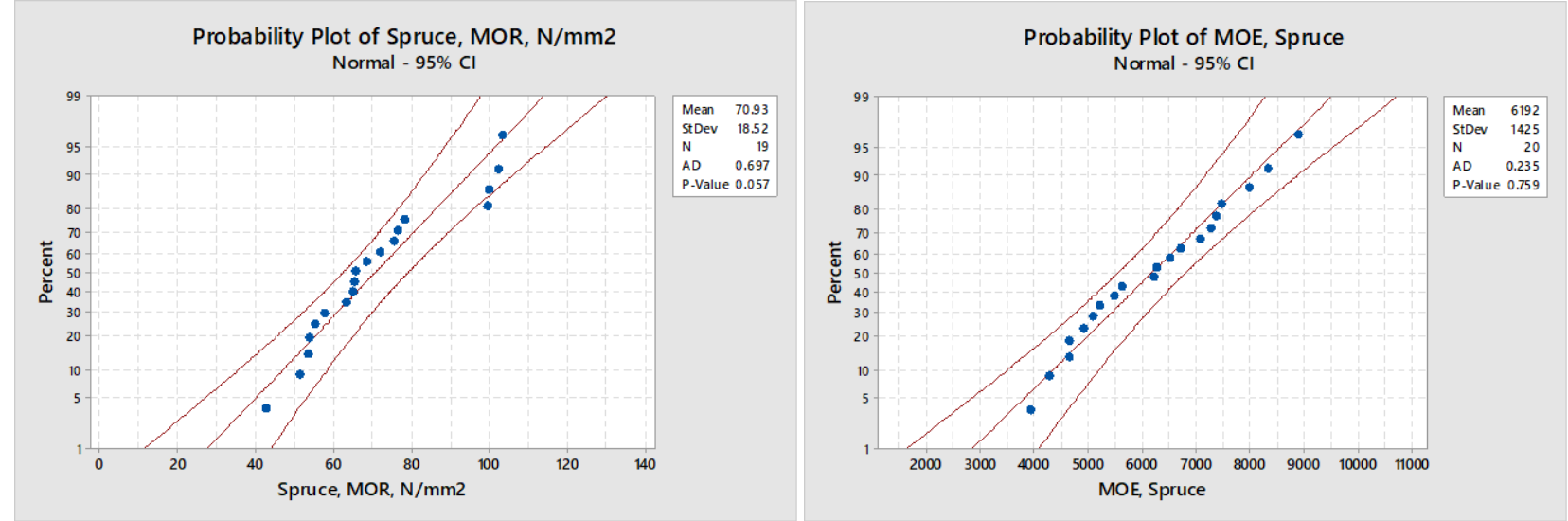

Fig. 4. MOR and MOE for Spruce species 
If a comparison is made between 3 specie (Figure 5), a tendency is visible, respectively spruce specie is the best, from the point of view of MOR and MOE of bending strength.
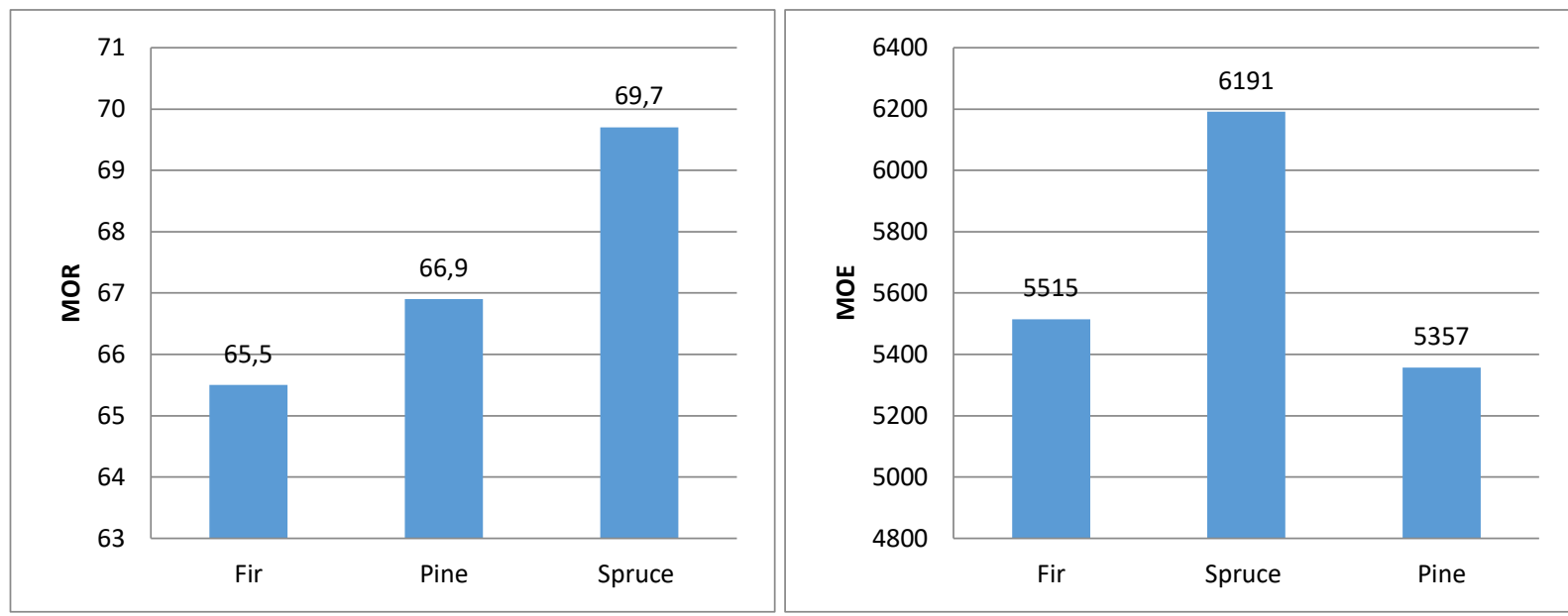

Fig. 5. MOR and MOE comparison for all three wooden species

By concatenating all the values obtained in the paper, visible in Table 1, it is observed that although generally all three wood species are used in the OSB industry, there are still some species that are better (spruce) and other two on the same place (pine and fir).

Table 1. Comparison between resinous specie used in OSB industry (considering that "weak + very good = 2 good")

\begin{tabular}{|l|l|l|l|l|l|l|}
\hline Specie & Absorption & Swelling & Density & MOR & MOE & TOTAL \\
\hline Fir & very good & weak & weak & weak & good & 3 good +2 weak \\
\hline Pine & weak & good & good & good & weak & 3 good +2 weak \\
\hline Spruce & good & very good & very good & very good & very good & 4 very good +1 good \\
\hline
\end{tabular}

\section{Conclusions}

1. Most properties of softwood species have very good values, above those required by the standards in the field (EN 300).

2. Higher values of bending strength (MOR) and modulus of elasticity (MOE) of raw wood could lead to higher strengths of OSB boards. The properties of the solid wood influence only to a certain extent the properties of the obtained boards, because the solid wood is transformed into chips, from this point of view the OSB board is a reconstituted product.

3. The mixture of species used in the manufacture of OSB boards, if it is softwoods (fir, spruce and pine), could be a solution for obtaining good resistance of OSB boards, because spruce wood is much cheaper than pine;

4. The softwood species used in the work (fir, spruce, pine) has low densities, which will lead to a good compaction and compression of the chips within the OSB boards.

\section{References}

1. ISO 16864 (2001): Wood-based panel -Oriented Strand Board (OSB) - Definitions, classification, specifications. International Organization for Standardization, https://www.iso.org/standard/32475.html

2. EN 300 (2006): Oriented Strand Boards (OSB) - Definitions, Classification and Specifications. European Committee for Standardization, Brussels, https://apawood-europe.org/official-guidelines/europeanstandards/individual-standards/en-300/

3. Barnes D. (2000): An integrated model of the effect of processing parameters on the strength properties of oriented strand wood products. Forest Product Journal, ISSN 0015-7473, vol. 50, is. 11, p. 33-42, https://go.gale.com/ps/anonymous?id=GALE\%7CA71325060\&sid=googleScholar\&v=2.1\&it=r\&linkaccess= abs\&issn $=00157473 \& p=A 0 N E \& s w=w$ 
4. Beck K., Cloutier A., Salenikovich A., Beauregard R. (2009): Effect of strand geometry and wood species on strandboard mechanical properties. Wood and Fiber Science, ISSN 0735-6161, vol. 41, is. 3, p. 267-278, https://pdfs.semanticscholar.org/1154/da5f70995cacaa1a29c89fe20d9874573b48.pdf

5. Bufalino L. (2015): Alternative compositions of Oriented Strand Boards (OSB) made with commercial woods produced in Brazil. Maderas. Ciencia y tecnología, ISSN 0718-221X, Vol. 17, is. 1, p. 105-116, http://dx.doi.org/10.4067/S0718-221X2015005000011

6. Dixon P.G., Malek S., Semple K.E., Zhang P.K., Smith G.D., Gibson L.J. (2017): Multiscale modelling of moso bamboo oriented strand board. BioResources, ISSN 1930-2126, Vol. 12, is. 2, p. 3166-3181, DOI: 10.15376/ biores.12.2.3166-3181

7. EN 323 (1993): Wood-based panels - Determination of density. European Committee for Standardization, Brussels, https://www.en-standard.eu/bs-en-323-1993-wood-based-panels-determination-of-density/

8. EN 317 (1993): Particleboards and fiberboards. Determination of swelling in thickness after immersion in water. European Committee for Standardization, Brussels 